\title{
BERNARDO O'HIGGINS Y SU DULCE DESTIERRO. EL NEGOCIO DEL AZÚCAR EN TIERRAS PERUANAS Y SUS INTERESES EN LA GUERRA DE CHILE CONTRA LA CONFEDERACIÓN PERÚ-BOLIVIANA (1836-1839)
}

\author{
Gonzalo Serrano del Pozo* \\ Centro de Estudios Americanos \\ Universidad Adolfo Ibáñez (Chile)
}

El presente artículo tiene como objetivo analizar la postura del general Bernardo O'Higgins durante la guerra de Chile contra la Confederación Perú-Boliviana. La revisión de su epistolario, mientras estuvo en Perú, dejaría en evidencia que sus intereses económicos fueron claves al momento de tener que determinar el apoyo a uno u otro bando. Más allá de la mirada idealizada en contra del conflicto, que sus defensores han buscado destacar, se esconde un hombre pragmático, preocupado de resguardar sus intereses particulares.

\section{Palabras claves: Bernardo O'Higgins-Diego Portales- comercio de azúcar-Guerra contra la Confederación}

\section{BERNARDO O'HIGGINS AND HIS SWEET UNDERGROUND. THE BUSINESS OF SUGAR IN PERUVIAN LAND AND ITS INTERESTS IN THE WAR OF CHILE AGAINST THE PERU-BOLIVIAN CONFEDERATION (1836-1839)}

The objective of this article is to analyze the position of General Bernardo O'Higgins during the Chilean War against the Peru-Bolivian Confederation. The review of their correspondence, while he was in Peru, would leave in evidence that economic interests were the key at the time of having to determine support for one side or the other. Beyond the idealized look against the conflict, which its defenders have sought to highlight, hides a pragmatic man, anxious to protect their interests.

Keywords: Bernardo O'Higgins-Diego Portales- trade in sugar- Peru-Bolivian Confederation

Artículo Recibido: 20 de Febrero de 2018 Artículo Aceptado: 22 de Mayo de 2018

*E-mail: gserrano@uai.cl 


\section{Introducción}

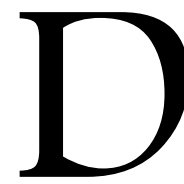

urante la época colonial, las relaciones entre Chile y Perú estuvieron marcadas por la dependencia económica, situación que se fue acentuando en la etapa republicana ${ }^{1}$. Claudio Gay establece el terremoto acaecido en Perú el año 1687, como un hito en la historia comercial de ambos países, cuando las tierras dejaron de producir la cantidad de trigo que se necesitaba y hubo que comenzar a recurrir a Chile para abastecerse ${ }^{2}$. A su vez, Chile dependía del azúcar de caña que se producía en Perú.

Una vez que ambos países alcanzaron la independencia, la relación comercial se mantuvo. Sin embargo, hacia la década del treinta, las presiones de diversos sectores, incluyendo los extranjeros que querían aprovechar los beneficios de la apertura económica, generaron una tensión que se manifestó en la llamada guerra de los impuestos y que no cesó hasta la elaboración de un Tratado de Libre Comercio ${ }^{3}$.

\footnotetext{
${ }^{1}$ La relación comercial entre Perú y Chile, sus complejidades e intereses contrapuestos ha sido estudiado a través del circuito comercial entre Tacna y Arica desde fines del siglo XVIII hasta mediados del siglo XIX por Rossenblit, Jaime, Centralidad Geográfica, marginalidad política: la región de Tacna y Arica y su comercio 1778-1841, DIBAM y Centro de Estudios Barros Arana, Santiago, 2013.

${ }^{2}$ Gay, Claudio, La agricultura chilena, Cámara Chilena de la Construcción - PUCCH - DIBAM, Santiago, 2009, p. 18.

3 Este tema ha sido ampliamente desarrollado en los siguientes trabajos: Serrano, Gonzalo, 1836-1839. Portales y Santa Cruz. Valparaíso y la Guerra contra la Confederación, Ediciones Universitarias de Valparaíso, Valparaíso, 2013 y Cavieres, Eduardo y Serrano, Gonzalo, «La guerra de Chile contra la Confederación PerúBoliviana (1836-1839): el trigo y la agricultura como bases de un proyecto nacional», Revista América Latina en Historia Económica, vol. 25, n 1, 2018 (pp. 136-164).
} 
El rechazo a este acuerdo por parte de la Confederación Perú Boliviana, liderada por el general boliviano Andrés de Santa Cruz, habría sido un factor fundamental en la declaración de guerra de Chile a la Confederación en diciembre de 1836.

En esta línea, resulta interesante conocer la situación en que se encontraba Bernardo O’Higgins en Perú, sus intereses y la actitud que conservó respecto al gobierno del general José Joaquín Prieto, al rol de Diego Portales, a la formación de la Confederación y frente a la guerra y ocupación posterior.

La amplia historiografía desplegada en torno al prócer de la independencia ${ }^{4}$, ha considerado en líneas separadas la postura de O’Higgins sobre la Confederación y su gestor, el general Andrés de Santa Cruz, y su relación con la agricultura mientras estuvo desterrado en Perú, como si no pudieran ser parte de un mismo problema. La mayoría de las biografías se ha centrado en aspectos relacionados con su rol en las guerras de independencia y su gobierno, dejando de lado esta arista menos conocida de su vida: su rol como comerciante durante el tiempo que vivió en Perú.

Un análisis general nos permite asegurar que la actitud de O’Higgins frente a la Confederación y la guerra estaba condicionada por sus intereses económicos, de manera específica, el negocio del azúcar. Desde un punto de vista político, la mirada crítica sobre el general Prieto, el Ministro Portales y la misma guerra, se atenuó luego de mantener contacto con el general Manuel Bulnes, mientras se conservó la presencia del Ejército Restaurador en Perú. El apoyo otorgado a la última parte de la campaña, la restauración de los grados y la opción de que el general regresara a Chile son testimonio de este cambio, los que habrían estado condicionados por asegurar su situación personal, política y económica.

\footnotetext{
${ }^{4}$ Hay varias obras que han estudiado a Bernardo O'Higgins desde sus orígenes hasta su renuncia al cargo de Director Supremo en 1823: Bello, Juan, Don Bernardo O'Higgins, Galería Nacional y Colección de Biografías y Retratos de Hombres Célebres de Chile, dirigida y publicada por Narciso Desmadryl, Santiago, 1854 (pp. $70-$ 107); Vicuña Mackenna, Benjamín, El Ostracismo del Jeneral D. Bernardo O’Higgins, Imprenta i Librería del Mercurio, Valparaíso, 1860; Amunátegui, Miguel Luis y Vicuña Mackenna, Benjamín, Vida del General don Bernardo O'Higgins (Su Dictadura- Su Ostracismo), Editorial Rafael Jover, Santiago, 1882; Vicuña Mackenna, Benjamín, Vida de O'Higgins, Universidad de Chile, Santiago, 1936; Campos Méndez, Enrique, Bernardo O’Higgins. El Padre de la Patria, Editorial EMECÉ, Buenos Aires, 1942; Campos Harriet, Fernando, La vida heroica de O'Higgins, Esc. Tip. La Gratitud Nacional, Santiago, 1947; Eyzaguirre, Jaime, O'Higgins, Zigzag, Santiago, 1950; Fernández, Sergio, O’Higgins, Editorial Orbe, Santiago, 1974; Valencia, Luis, El Pensamiento de O'Higgins, Editorial del Pacífico, S.A., Santiago, 1974 y Clavel, Roberto, «Una biografía de Bernardo O’Higgins Riquelme», Bernardo O'Higgins: Retrospectiva histórica y herencia del padre de la Patria, Universidad Bernardo O’Higgins, Santiago, 2009 (pp. 9-50), por nombrar solo las más relevantes.
} 
Las fuentes para este trabajo se han centrado en sus cartas ${ }^{5}$ y estudios anexos sobre esta guerra, que permiten ir conformando el marco general en el que este intercambio epistolar se llevaba a cabo6 ${ }^{\text {. }}$

\section{Bernardo O’Higgins y el negocio del azúcar}

Posterior al destierro político, Bernardo O’Higgins tuvo que buscar la forma para subsistir en Perú. En agradecimiento a su rol en la independencia, recibió del Gobierno peruano dos haciendas, las de Cañete y Montalván. Esta última, expropiada a un oficial español, había sido donada a O'Higgins por Decreto Supremo durante la dictadura de San Martín en $1822^{7}$.

Sin estos terrenos, recuerda José María de la Cruz, el general habría tenido que mendigar el sustento para él y su familia, pues sus enemigos habían buscado el medio de privarlo de los únicos bienes que le quedaban en Chile, la hacienda Las Canteras, y el miserable sueldo que le correspondía ${ }^{8}$.

Bernardo O'Higgins ya antes había manifestado su gusto por la agricultura y afirmaba que de no haber sido por las circunstancias políticas en que se vio envuelto, su vida se habría desarrollado en torno al campo. A inicios del siglo XIX, luego de su viaje a Europa y por herencia de su padre, O’Higgins se hizo cargo de la hacienda San José de Las Canteras, que mencionaba De la Cruz. La relevancia comercial de esta propiedad lo fue involucrando con la vida pública, primero como alcalde, luego como miembro del Cabildo y, posteriormente, como soldado por la independencia. Sin embargo, su lucha contra los realistas tuvo consecuencias irreparables para su hacienda, que terminó con sus casas quemadas y campos talados.

Quince años más tarde y luego de una serie de acontecimientos, Bernardo O’Higgins se encontraba lejos de su patria, de nuevo en el campo y dependiendo únicamente de su trabajo para poder subsistir.

\footnotetext{
${ }^{5}$ En este artículo trabajaremos esencialmente con la última edición de sus cartas publicadas por: O’Higgins, Bernardo, Guerrero, Cristián y Miño, Nancy (editores), Cartas de Bernardo O'Higgins, editorial Historia Chilena, Santiago, 2011. En adelante Cartas de O'Higgins.

${ }^{6}$ Carmen Mc Evoy y José Luis Rénique destacan la importancia de los epistolarios para conocer aspectos desconocidos de las vidas de los militares que administraron la república y el proceso de gestación de estas. Mc Evoy, Carmen y Rénique, José Luis, Soldados de las República. Guerra y correspondencia y memoria en el Perú (1830-1844), Fondo Editorial del Congreso del Perú e Instituto Riva-Agüero, Lima, 2010.

7 Fernández, Sergio, op. cit., p. 161.

${ }^{8}$ Carta de José María de la Cruz a Miguel Luis Amunátegui, julio 7 de 1853. De la Cruz, José María, Recuerdos de Don Bernardo O'Higgins, Introducción y notas de Jaime Eyzaguirre, Editorial Andrés Bello, Santiago, 1960, pp. 53-54.
} 
Gracias a estas propiedades, en especial la hacienda de Montalván, a mediados de la década del 30, los intereses de Bernardo O’Higgins, como se puede deducir de sus cartas, estaban puestos en el negocio del azúcar. La mayoría de las misivas enviadas a Rosa O’Higgins, Carlos Durán, José Toribio Pequeño escritas desde la Hacienda de Montalván, dejan en evidencia que para esos años, había entrado de lleno en este negocio.

Es en este punto donde los caminos de Bernardo O’Higgins y Diego Portales comienzan a intersectarse. La desconfianza y diferencias entre ambos personajes, si bien pueden fundamentarse en razones de carácter político, poseen una veta menos explorada, la comercial.

La postura de Portales representaba al ala más dura del Gobierno y apostaba a una competencia agresiva con Perú que le permitiera mantener la hegemonía de Valparaíso sobre Callao en el Pacífico Sur. Por el contrario, la oligarquía conservadora, compuesta en su mayoría por los criollos terratenientes ${ }^{9}$, consideraba que era necesario consolidar las relaciones comerciales con Perú mediante un acuerdo que dejara a ambos países en una situación de preferencia respecto a otras naciones.

No obstante, el lento proceso de organización de Perú, luchas políticas e intereses particulares, entramparon las posibilidades de firmar un tratado. Los extranjeros buscaban liberalizar el comercio, en contraposición a los nacionalistas, que querían proteger la industria local ${ }^{10}$. Los hacendados del norte temían por el fin de la esclavitud ${ }^{11}$, mientras que algunos caudillos, como Agustín Gamarra, participaban activamente del monopolio de la harina ${ }^{12}$. En definitiva, como explica Monroy, la sociedad peruana estaba fragmentada en espacios regionales, cada uno con su propia dinámica ${ }^{13}$.

A pesar de estas diferencias, se había logrado consolidar un sistema de intercambio entre Chile y Perú, basado en el comercio de trigo y azúcar. Sin embargo, la relación se quebró cuando el gobierno peruano decretó, en junio de 1832, que el trigo chileno que fuera desembarcado en Lima, debía ser medido y despachado de forma inmediata, una

9 Cariola, Carmen y Sunkel, Osvaldo, Un siglo de Historia Económica de Chile 1830-1930, Editorial Universitaria, Santiago, 1990, p. 24.

${ }^{10}$ Bonilla, Heraclio, «Perú y Bolivia», en Bethell, Leslie, Historia de América Latina, vol. 6, Editorial Crítica, Barcelona, 1991, Cap. 6, p. 208.

11 Sobrevilla, Natalia, The caudillo of the Andes, Cambridge, Cambridge (United States of America), 2011, p. 128.

${ }^{12}$ Basadre, Jorge, Historia de la República del Perú, Editorial Panamericana, Lima, 1963, Tomo I, p. 308.

13 Monroy, Gustavo, La Confederación Perú-Boliviana, Fondo Editorial Universidad de Ciencias y Humanidades, Lima, 2013, p. 17. 
acción hostil e impracticable ${ }^{14}$ que, según Parkerson, tenía por objeto perjudicar el trigo y la harina chilena en el mercado peruano ${ }^{15}$.

Diego Portales fue uno de los promotores en contrarrestar estos ataques por intermedio de una política agresiva con respecto a Perú y apostó por establecer un fuerte impuesto a los azúcares peruanos. En efecto, Portales advertía que este gravamen podría conducir a un conflicto para el que el país no se encontraba lo suficientemente preparado, desde el punto de vista militar:

Hemos puesto los azúcares peruanos 3 pesos en arroba, resolución que puede muy bien arrancar o mover al Gobierno peruano a tomar la medida de gravar por ejemplo con un 20\% las mercaderias que se internasen en sus puertos después de haber pasado por el de Valparaíso, y he de aquí un paso que destruiria nuestros almacenes de depósito y nuestro comercio, y entonces no habría otro recurso que volver atrás con la más vergonzosa degradación, y liberarles los azúcares de todo derecho si así lo querían los peruanos o irnos sobre ellos con un ejército ${ }^{16}$.

En este contexto, se justifica la preocupación de O’Higgins frente a este tema. El prócer de la independencia intentaba explicar las restricciones del gobierno peruano a los envíos de trigo chilenos y desacreditar las críticas expuestas por el grupo que lideraba Diego Portales, a través de El Mercurio de Valparaíso, recurriendo a la descalificación del personaje:

No haria estas observaciones si no estuviera plenamente convencido del desprecio con que son mirados esos escritores aviesos, que no habiendo derramado su sudor o su sangre ni agotado sus tesoros por la causa común de América, tan despiadadamente se empeñan

\footnotetext{
${ }^{14}$ Izquierdo, Gonzalo, Historia de Chile, Editorial Andrés Bello, Santiago, 1990, Tomo II, p. 136.

${ }^{15}$ Según cálculos de Parkerson, hacia 1835, las exportaciones de trigo y harina de Chile a Perú totalizaban unos $\$ 405.124$ pesos por año, lo que equivalía al $76 \%$ del valor de su comercio con el Perú. Las exportaciones chilenas, en tanto, eran compensadas con productos peruanos, principalmente azúcar y tabaco, que para ese mismo año totalizaron \$351.423. Parkerson, Phillip, Andrés de Santa Cruz y la Confederación Perú-boliviana 1835-1839, Librería Editorial Juventud, La Paz, 1984, pp. 161-162.

${ }^{16}$ Carta de Diego Portales a Antonio Garfias, Valparaíso, agosto 30 de $1832, \mathrm{~N}^{\circ} 280$, en Epistolario de Diego Portales, edición a cargo de Carmen Fariña, Ediciones Universidad Diego Portales, Santiago, 2007, Tomos I y II, p. 316.
} 
en deshonrarla en sus héroes, que son columnas las más fuertes de sus estados ${ }^{17}$.

La inestabilidad del mercado que generaba la política agresiva liderada por Portales, obligó a O’Higgins a diversificar el negocio. En una misiva del 12 de septiembre de 1834, O’Higgins manifestaba sus dudas respecto al valor de venta de los panes de azúcar, antes de conocer el precio al que se estaba comercializando este producto en Chile, frente a lo cual solicitó el envío de barriles de ron considerando: «que es el artículo que puede sacarnos de apuros» ${ }^{18}$.

La revisión de las cartas dirigidas a uno de sus administradores, Carlos Durán, durante los años 1834 y 1835, versan sobre este tipo de temáticas. El otrora héroe de la independencia aquí aparecía vendiendo panes de azúcar, encargando ron, otro de sus productos estrella, comprando sebo, tamarindos, clavos, frazadas, etc ${ }^{19}$. Consecuente con esto, cualquier cambio en las condiciones políticas y comerciales podía afectar su negocio y mermar su fragilidad económica. De ahí que los hechos que condujeron a la guerra terminaron siendo para O'Higgins, no solo desde un punto de vista político, un problema particular.

La guerra de impuestos, a la que hacíamos referencia, derivó en un acercamiento entre las partes, que buscaron, por intermedio de un tratado, poner fin a una disputa que iba en contra de la historia y los intereses de algunos sectores. En el caso chileno, la oligarquía terrateniente y, en el peruano, los hacendados del norte ${ }^{20}$.

${ }_{17}$ Carta de Bernardo O’Higgins a José Joaquín Prieto, Lima, 20 de octubre de 1832. Epistolario, II, 17, 171173. Archivo de don Bernardo O'Higgins, XXXII, 107-109, Cartas de O'Higgins..., op. cit., Tomo II, p. 292.

${ }^{18}$ Carta de Bernardo O'Higgins a Carlos Durán, Hacienda de Montalván, 12 de septiembre de 1834. Archivo de don Bernardo O'Higgins, XXXII, 1884-185, Ibidem, Tomo I, p. 271.

${ }^{19}$ Carta de Bernardo O'Higgins a Carlos Durán, Hacienda de Montalván, 10 de enero de 1835. Archivo de don Bernardo O'Higgins, XXXII, 186, Ibidem, Tomo I, p. 272; Carta de Bernardo O'Higgins a Carlos Durán, Hacienda de Montalván, 3 de febrero de 1835. Archivo de don Bernardo O'Higgins, XXXII, 187, Idem.; Carta de Bernardo O'Higgins a Carlos Durán, Hacienda de Montalván, 10 de febrero de 1835. Archivo de don Bernardo O'Higgins, XXXII, 187-188, Ibidem, Tomo I, p. 273; Carta de Bernardo O'Higgins a Carlos Durán, Hacienda de Montalván, 12 de febrero de 1835. Archivo de don Bernardo O'Higgins, XXXII, 189, Ibidem, Tomo I, p. 274; Carta de Bernardo O’Higgins a Carlos Durán, Hacienda de Montalván, abril 23 de 1835. Archivo de don Bernardo O'Higgins, XXXII, 190, Idem.; Carta de Bernardo O'Higgins a Carlos Durán, Hacienda de Montalván, 11 de mayo de 1835. Archivo de don Bernardo O'Higgins, XXXII, 190-191, Ibidem, Tomo I, p. 275; Carta de Bernardo O'Higgins a Carlos Durán, Hacienda de Montalván, 125 de agosto de 1835. Archivo de don Bernardo O'Higgins, XXXII, 191, Ibidem, Tomo I, p. 276 y Carta de Bernardo O'Higgins a Carlos Durán, Hacienda de Montalván, 14 de noviembre de 1835. Archivo de don Bernardo O'Higgins, XXXII, 192, Idem.

${ }^{20}$ Gottenberg, Paul, Caudillos y comerciantes, Centro de Estudios Regionales Andinos «Bartolomé de Las Casas», Perú, 1997, p. 84. 
Bajo estos principios, se elaboró el Tratado de amistad, comercio y navegación entre ambas repúblicas, que debía ser ratificado por los respectivos congresos, pero que en el caso peruano coincidió con la lucha entre sus principales caudillos: Luis José Orbegoso, Agustín Gamarra y Felipe Salaverry. No siendo nuestro objetivo centrarnos en esta disputa, vale la pena mencionar que el triunfo de Orbegoso, obtenido gracias al apoyo de Santa Cruz, cambió la mirada peruana respecto a este acuerdo.

La política de la Confederación consistía en abrir la economía peruana al mundo, competir con Valparaíso como puerto principal del Pacífico, y aprovechar las buenas relaciones del Mariscal Santa Cruz con Gran Bretaña y Francia. De acuerdo al informe que justificaba el rechazo al tratado y que fue confeccionado por el Ministro de Hacienda de Orbegoso, el colombiano Juan García del Río, este acuerdo beneficiaba artificiosamente a los productores de azúcar:

Es necesario advertir que el único producto de nuestra agricultura beneficiado por el tratado en cuestión es la azúcar (...) Mas, aquel beneficio es momentáneo. Ciertamente que no se pretenderá negar que el precio actual del azúcar en el mercado no puede considerarse como su valor de ordinario (...) También se concederá que aquel precio subido no puede mantenerse, porque no es dable que haga cuenta a los especuladores la introducción de más azúcares del Perú en Chile, cuando no es practicable asegurar su monopolio allá (...) a los hacendados de las cañas les están abiertos otros mercados para sus productos, y es fuerza que los busquen, porque de lo contrario, y si han de sacrificarse siempre a sus intereses generales, jamás podrá florecer el Perú, porque recibirá de Chile la ley a truque de enviar allí sus azúcares ${ }^{21}$.

El ministro de Hacienda de la Confederación concluía su informe señalando que los productores de azúcar debían concentrar sus esfuerzos en otros mercados, en especial, Bolivia y Gran Bretaña.

El Araucano, periódico oficial del Gobierno chileno, respondió el rechazo argumentando que el tratado no favorecía mayormente al comercio de este país, como sí lo

\footnotetext{
${ }^{21}$ Informe de Juan García del Río en Sotomayor Valdés, Ramón, Historia de Chile, Academia Chilena de la Historia, 1965, Tomo II, pp. 91- 92.
} 
hacía con los azúcares peruanos, que según este periódico: «han disfrutado completamente la rebaja de derecho en los puertos chilenos, mientras que nuestro comercio de granos ha estado sujeto en el Callao a providencias arbitrarias» 22 .

Más allá de las diferencias, la relación comercial entre Chile y Perú, ahora representado por la Confederación, regresó al punto original en que los trigos chilenos pagaban un derecho de introducción de dos pesos por fanega y las harinas de cinco pesos y se amenazaba con subirlos aún más si es que Chile cobraba por el azúcar peruana más de los dos tercios de los derechos que pagaba a la nación más favorecida.

Aunque no hay registro de cartas publicadas por Bernardo O'Higgins sobre este acuerdo, a partir de las misivas que enviaba al mismo Durán en 1836, queda la sensación de que la actividad se mantuvo de la misma manera durante ese año.

Sin embargo, a mediados de 1837, en una carta dirigida nada menos que al mismísimo general Santa Cruz, O’Higgins empieza a manifestar su preocupación por los inconvenientes que podía generar en el comercio, la guerra en que se había empecinado el «infatuado» ministro y su círculo:

\section{Si los soldados de la fábrica de don Diego Portales nos amenazan en este valle, antes de mediados del mes de entrante de junio, habrá que abandonarlo todo, y tomar providencias para salvar los ganados al interior con cuanto se pueda, operación en que indudablemente se perderá una mitad por falta de pastos en la marcha; y en cuanto a mi corta cosecha de azúcares, desde hoy mismo estoy buscando recuas que los conduzcan a Lima ${ }^{23}$.}

De acuerdo a lo que se puede observar, y pese a la preocupación del general O’Higgins, el precio del azúcar, cuatro pesos la arroba ${ }^{24}$, permaneció estable hasta mediados de 1837, hasta que el Ejército Restaurador comenzó a asolar las costas peruanas. Así queda de manifiesto en una carta a su hermana, Rosa O'Higgins, en la que confiesa que habían comenzado a sentir los efectos de una «guerra fratricida y tan injusta como son perversos sus promotores». Junto con esto, informaba que se había enviado una orden para

\footnotetext{
${ }^{22}$ El Araucano, 5 de febrero de 1836.

${ }^{23}$ Carta de Bernardo O'Higgins a Andrés de Santa Cruz, Hacienda de Montalván, 20 de mayo 1837. Archivo de don Bernardo O'Higgins, XXXII, 216-218, Cartas de O'Higgins... , op. cit., Tomo III, pp. 207-208.

${ }^{24}$ Carta de Bernardo O’Higgins a Carlos Durán, Callao, 16 de marzo de 1837. Archivo de don Bernardo O’Higgins, XXXII, 211-212, Ibidem, Tomo I, p. 283.
} 
retirar los ganados. No había pasto y más de trescientas vacas podían perderse, luego de haberlas criado, dice el general, durante trece años de sacrificios. Finalmente, advierte que era urgente enviar el azúcar que les quedaba a Lima para no perderla ${ }^{25}$.

En el mismo tono, escribe a su amigo Juan Thomas, informando que, por suerte para sus intereses, la expedición chilena había desembarcado en Arica y no en Lima, lo que habría significado la pérdida de todo lo que había en su hacienda y también de su ganado ${ }^{26}$. Este tema se repite en otra carta escrita a su hermana Rosa O'Higgins en la que especula que el teatro de operaciones iba a ser Arequipa ${ }^{27}$.

Las cartas posteriores a la primera expedición demuestran la incertidumbre que se generó en torno a esta campaña y los problemas económicos que esto implicó. O’Higgins comenta a su hermana que el hecho de haberse quedado en la hacienda permitió dar tranquilidad al resto de los hacendados y seguir haciendo funcionar el negocio. De lo contrario, asegura, los gañanes y esclavos se habrían retirado y el ganado habría sufrido pérdidas considerables y concluye: «Así, pues, mientras no hayan otras evidencias que las presentes, pienso continuar mis trabajos hasta acabarlos. No por eso dejo de estar en vigilancia de un soldado en campaña, que espera una sorpresa» 28 , advierte a Rosa.

A partir de la correspondencia con otro de sus administradores, José Toribio Pequeño, se puede verificar de qué forma Bernardo O'Higgins fue interiorizándose y perfeccionándose en el negocio del azúcar y como la incursión chilena comenzó a afectarles $^{29}$.

La preocupación se incrementó cuando advertía a Pequeño: «Sin azúcares pasaremos las penas del purgatorio. Hay mucho que pagar y dinero a interés no se encuentra» ${ }^{30}$. Al parecer, la producción y venta de azúcar se detuvo durante el mes de mayo y junio, lo que generó un desajuste en las cuentas del general, hecho que se agravó por la

\footnotetext{
${ }^{25}$ Carta de Bernardo O'Higgins a Rosa O’Higgins, Montalván, 7 de octubre de 1837. Epistolario, II, 219-220, Ibidem, Tomo II, p. 131.

${ }^{26}$ Carta de Bernardo O'Higgins a Juan Thomas, Montalván, 10 de octubre de 1837. Epistolario, II, 220-221. Archivo de don Bernardo O'Higgins XXXII, 222-223, Ibidem., Tomo III, p. 241.

27 Carta de Bernardo O'Higgins a Rosa O'Higgins, Montalván, 11 de octubre de 1837. Archivo de don Bernardo O'Higgins, XXXII, 224-225, Ibidem, Tomo II, pp. 132-133.

${ }^{28}$ Carta de Bernardo O'Higgins a Rosa O'Higgins, Montalván, 17 de octubre de 1837. Epistolario, II, 221-223 Archivo de don Bernardo O'Higgins, XXXII, 242-243, Ibidem, Tomo II, pp. 156-157.

${ }^{28}$ Carta de Bernardo O'Higgins a José Toribio Pequeño, Lima, 27 de agosto de 1838. Archivo de don Bernardo O'Higgins, XXXII, 225-227, Ibidem, Tomo II, p. 133.

${ }^{29}$ Carta de Bernardo O'Higgins a José Toribio Pequeño, Montalván, 18 de abril de 1838. Archivo de don Bernardo O'Higgins, XXXII, 242-243, Ibidem, Tomo II, pp. 156-157.

${ }^{30}$ Carta de Bernardo O’Higgins a José Toribio Pequeño, Lima, 19 de julio de 1838 . Archivo de don Bernardo O'Higgins, XXXII, 257, Ibidem, Tomo II, p. 161.
} 
presencia de la segunda expedición en Perú, tal como queda en evidencia en una carta posterior: «A la hora de su partida comenzó aquí la batalla, y en ésta, su casa, no ha habido la menor novedad. La pobreza nos aniquila y no hay quien preste» ${ }^{31}$.

El panorama comenzó a cambiar a fines del mismo año y O’Higgins veía con optimismo el desarrollo de los acontecimientos:

\section{La guerra obstruye los caminos y la movilidad y por eso no hay} ventas como en tiempos de tranquilidad; pero cada día más se tranquilizan las cosas y no tardará en abrirse venta de chancaca como antes. Mientras tanto no dudo se sufrirán escaseces de numerario para pagar gañanes, segadores y tapieros ${ }^{32}$.

O’Higgins, ignorante de que la guerra había finalizado favorable al Ejército Restaurador en los campos de Yungay, el 20 de enero de 1839, mantenía su preocupación por el estado de los caminos, unos días después ${ }^{33}$.

Junto con esto, el prócer manifestaba su inquietud ante la posibilidad de que los trabajadores de su hacienda no fuesen obligados a ser reclutados para la guerra. En base a sus influencias, envió una orden del Supremo Gobierno a José Toribio Pequeño para que dieciséis de sus peones fueran «excepcionados» del reclutamiento militar. La preferencia, indicaba, debía estar puesta en beneficiar a los regadores y gañanes ${ }^{34}$.

Esta carestía, como él mismo lo confiesa en otra de sus cartas a Pequeño, lo obligó a incursionar, además del azúcar y el trigo, en la ganadería. Así queda de manifiesto cuando hablaba de treinta bueyes y cuarenta vacas que, a fines de 1838, necesitaba vender para:

\footnotetext{
${ }^{31}$ Carta de Bernardo O'Higgins a José Toribio Pequeño, Lima, 27 de agosto de 1838. Archivo de don Bernardo O'Higgins, XXXII, 259, Ibidem, Tomo II, pp. 162-163.

${ }^{32}$ Carta de Bernardo O'Higgins a José Toribio Pequeño, Lima, 28 de noviembre de 1838. Archivo de don Bernardo O'Higgins, XXXII, 271 y 272, Ibidem, Tomo II, pp. 168-169.

33 Carta de Bernardo O'Higgins a José Toribio Pequeño, Lima, 23 de enero de 1839. Epistolario, II, 266-267. Archivo de don Bernardo O'Higgins, XXXII, 299-301, Ibidem, Tomo II, pp. 186-187.

34 Carta de Bernardo O'Higgins a José Toribio Pequeño, Lima, 12 de diciembre de 1838. Epistolario, II, 251. Archivo de don Bernardo O'Higgins, XXXII, 282, Ibidem, Tomo II, p. 173. Una situación similar se dio en Chile donde también se eximió a los labradores y gañanes de la recluta, sobre este tema recomendamos: Valdés, Magdalena, Reclutamiento, Orden y Corrección Social. Colchagua ante la Guerra contra la Confederación Peruano-Boliviana, Tesis para optar al grado de Licenciado en Historia (Profesora Guía Sol Serrano), Pontificia Universidad Católica de Chile, Santiago, 2007; Pinto, Julio, «¿La tendencia de la masa al reposo? El Régimen portaliano enfrenta al mundo plebeyo, 1830-1851», Revista Historia, n 44, vol. II, 2011 (pp. 401442) y Serrano, Gonzalo, Chile contra la Confederación, La Guerra en Provincias, Ril Editores, Valparaíso, 2017, pp. 55-65.
} 
«Salir de los apuros en que me encuentro por falta de dinero de contado, ya que la venta de azúcares es tan morosa» ${ }^{35}$.

La situación cambió una vez que se obtuvo la victoria. Ya con la tranquilidad del resultado, O'Higgins anunciaba a Pequeño el envío de un cargamento de azúcar a Chile aprovechando la rebaja en los derechos de internación ${ }^{36}$. Asimismo, sólo unos meses más adelante, solicitó a Pequeño el diseño de unos cajones para enviar azúcar a Chile, valiéndose del transporte que llevaría de regreso a las fuerzas que estaban al mando del general Cruz a mediados de $1839^{37}$.

A pesar de los beneficios que significaba el fin de la guerra y una buena relación con Chile, O’Higgins anunciaba que informaría al gobierno peruano de los perjuicios que su hacienda había sufrido por este conflicto y justificaba, como se deduce de esta carta, no haber aportado lo suficiente, pese a que, aseguraba, había ofrecido 500 arrobas en clase de empréstito ${ }^{38}$.

Independiente de la buena relación con la Confederación, no debe haber resultado cómodo para O'Higgins haber colaborado económicamente en un conflicto que enfrentaba a su tierra natal con la adoptiva.

\section{O’Higgins y la Confederación}

El epistolario del general Bernardo O’Higgins da cuenta del aprecio que tenía por el general boliviano Andrés de Santa Cruz y su idea de volver a unir a Perú y Bolivia en una Confederación ${ }^{39}$. Esto queda en evidencia en varias de sus cartas, en las que destacaba la figura del boliviano, su ejército y su proyecto ${ }^{40}$.

\footnotetext{
35 Carta de Bernardo O'Higgins a José Toribio Pequeño, Lima, 19 de noviembre de 1838. Archivo de don Bernardo O'Higgins, XXXII, 265-267, Cartas de O'Higgins..., op. cit., Tomo II, pp. 164-165.

${ }^{36}$ Carta de Bernardo O'Higgins a José Toribio Pequeño, Lima, 3 de mayo de 1839. Archivo de don Bernardo O'Higgins, XXXII, 315-316, Guerrero y Miño, Ibidem, Tomo II, pp. 195-196.

37 Carta de Bernardo O’Higgins a José Toribio Pequeño, Lima, 10 de junio 1839. Archivo de don Bernardo O'Higgins, XXXII, 324-327, Ibidem, Tomo II, pp. 200-202.

${ }^{38}$ Carta de Bernardo O’ Higgins a José Toribio Pequeño, Lima, 11 de junio de 1839. Archivo de don Bernardo O'Higgins, XXXII, 328, Ibidem, Tomo II, p. 203.

39 El 27 de mayo de 1836 Bernardo O'Higgins anunciaba a su amado amigo y compañero, José de San Martín, el nombramiento de Santa Cruz como Protector del Estado Sud-Peruano en federación con el Estado boliviano y la próxima unión del Estado Nor-Peruano: «Diez mil bayonetas apoyan, según dicen, esta unión, y tendrá, por consiguiente, la aprobación de los pueblos». Carta de Bernardo O'Higgins a José de San Martín, Lima, 27 de mayo de 1836. Epistolario, II, 195-199, Ibidem, Tomo III, p. 195.

40 José María de la Cruz en sus recuerdos, señalaba que la relación de Bernardo O’Higgins y Andrés de Santa Cruz, decía que ésta, sin ser íntimas eran de consideración mutua y agrega: «sus relaciones desde el establecimiento de la Confederación se limitaron a dos visitas de etiquetas en las épocas en que Santa Cruz
} 
Bernardo O'Higgins destacaba, entre otras virtudes, la confianza que existía de parte de las potencias por este proyecto: «El general Santa Cruz parece decidido a cultivar la paz y la buena voluntad con todos sus vecinos lo que más pueda, y los comerciantes ingleses están particularmente ansiosos que tenga éxito en estos propósitos» ${ }^{41}$.

De igual forma, O’Higgins aseguraba que los temores que se difundian sobre Santa Cruz en Chile eran injustificados ${ }^{42}$, como le hacía ver al presidente Prieto en una de sus cartas: «Permítame, mi querido compadre, hacer una observación con respecto a los recelos y temores excitados sobre el poder del general Santa Cruz. Ninguno, creo verdaderamente, respeta y aprecia más que yo sus talentos y valor de sus tropas», no obstante, reitera su fidelidad a Chile y, asegura, que pese al poder de Santa Cruz, sus fuerzas no eran suficientes como para constituir una amenaza para Chile ${ }^{43}$.

Durante esta época, se produjo el desembarco de la primera expedición que estuvo al mando del general Manuel Blanco Encalada. Después de una serie de inconvenientes y ante la amenaza de ver a su ejército derrotado por la Confederación, se produjo el acuerdo de Paucarpata que evitaba el enfrentamiento entre ambos ejércitos. Después de conocer esta noticia, O’Higgins escribió a Santa Cruz:

\section{Salvar la vida de sus conciudadanos es la mayor virtud en el padre} de la patria. Paucarpata es testigo de esa verdad; de ese suelo venturoso brotarán a porfía los progresos de la civilización y humanidad (...) Cuanto celebro que el general Blanco se haya comportado con la noble franqueza que me indicat4.

\footnotetext{
estuvo en Lima». Carta de José María de la Cruz a Diego Barros Arana, Queime, mayo 22 de 1855, De la Cruz, José María, op. cit., pp. 140-141.

${ }^{41}$ Destinatario no identificado, Lima, 24 de agosto de 1836. Archivo de don Bernardo O'Higgins XXXII, 194196, Cartas de O'Higgins..., op. cit., Tomo III, p. 301.

${ }^{42}$ Luis Valencia en su trabajo el ideario de O'Higgins considera la posición del general uno de sus grandes errores: «No fue un hombre fuera de lo común ni menos un genio, y tuvo como todos, caídas y errores. Así es el caso de su posición ante el Mariscal Andrés de Santa Cruz». Valencia, Luis, op. cit., p. 136.

${ }^{43}$ Carta de Bernardo O'Higgins a José Joaquín Prieto, Callao, 6 de abril de 1837. Archivo de don Bernardo O'Higgins, XXXII, 213-215, Cartas de O'Higgins..., op. cit., Tomo II, pp. 296-297.

${ }^{44}$ Carta de Bernardo O'Higgins a Andrés de Santa Cruz, Hacienda de Montalván, 1 de diciembre de 1837. Archivo de don Bernardo O'Higgins XXXII, 229-231, Ibidem, Tomo III, pp. 208-209. Esta acción, celebraba el prócer, era suficiente para olvidar los ataques que el general Blanco había dirigido antes contra su persona. Además de Santa Cruz, envió una carta al presidente Luis José Orbegoso para felicitarlo por el acuerdo: «Nunca podré explicar suficientemente, mi amado General, el gran placer que recibió mi alma al ver su estimable carta 29 del pasado, que me anuncia la paz definitiva con la República de Chile (...) Cordialmente me regocijo con V., mi amado General, porque el periodo de gozar la paz haya llegado tan pronto (...) nuestro común amigo el general Santa Cruz y V. están señaladamente escogidos por la mano del
} 
La felicidad del inicio se transformó en ira, cuando se enteró del rechazo al Tratado de Paucarpata: "iQué dolor! (...) iQué vergüenza!», fueron algunos de los términos mencionados en una carta dirigida al mismo Santa Cruz. El general buscaba de forma desesperada una explicación que le permitiera entender que, ya sin Portales en el camino, se insistiera en una lucha que consideraba fratricida y en la que el presidente chileno tenía una gran responsabilidad. Por esto mismo, no escatimaba en adjetivos contra el general Prieto, por haberse dejado llevar por oscuras maquinaciones:

Es de recelar haya alguna combinación secreta, que sale de lo escondido de donde nacen tan varios movimientos y cuyo oculto origen sobrepuja nuestro sentidos e inteligencia. Sin embargo, en cierto modo conduce a sospechar que tiende a derribar al precipicio al imbécil Prieto ${ }^{45}$.

Una vez que el Tratado fue ampliamente rechazado en Chile, se decidió llevar a cabo una nueva Expedición Restauradora, esta vez al mando del general Manuel Bulnes. Bernardo O'Higgins insistió, en un primer momento, con interceder en un nuevo arreglo pacífico. Con este fin, se comunicó con Bulnes, a quien muchos años antes había incitado a sumarse a la campaña libertadora ${ }^{46}$, para dar su mirada respecto del Protector de la Confederación, a quien conocía hace quince años y cuyas opiniones políticas eran favorables a la prosperidad de Chile ${ }^{47}$.

De forma paralela, intentaba explicar a Santa Cruz la compleja situación en que se encontraba personalmente debido al conflicto de dos países con los cuales tenía estrechos lazos. O'Higgins se veía como un hermano que miraba a otros dos enfrentados en una lucha: «¿Cuál debería ser la conducta de este buen hermano en tales circunstancias?

Todopoderoso para salvar los pueblos confederados de iguales desventuras y conducirlos a su prosperidad y dicha». Carta de Bernardo O'Higgins a Luis José Orbegoso, Hacienda de Montalván, 2 de diciembre de 1837. Archivo de don Bernardo O'Higgins, XXXII, 231-232, Ibidem, Tomo II, pp. 142-143.

45 Carta de Bernardo O'Higgins a Andrés de Santa Cruz, Hacienda de Montalván, 6 de febrero de 1838. Archivo de don Bernardo O'Higgins XXXII, 236-238, Ibidem, Tomo III, pp. 210-211.

${ }^{46}$ "Sí, mi amigo, tome usted parte en tan distinguida empresa». Carta de Bernardo O'Higgins a Manuel Bulnes, Fuerte de San Carlos, diciembre 7 de 1816. Epistolario, I, 60-61. Archivo de don Bernardo O'Higgins, VII, 80-81, Ibidem, Tomo I, p. 155.

47 Carta de Bernardo O'Higgins a Manuel Bulnes, Lima, 11 de noviembre de 1838. Epistolario, II, 243-244. Archivo de don Bernardo O'Higgins, XXXII, 262-263, Ibidem, Tomo I, p. 156. 
¿Permanecería inmóvil con los brazos cruzados (...)?»48. La respuesta, decía el mismo O’Higgins, era obvia. Debía interponer sus respetos, invocar a los hermanos para detener las armas, interponerse para mediar en crisis tan tremenda y que la guerra fratricida concluyera con una paz honrosa a ambas partes: «iEl cielo lo conceda!» ${ }^{49}$.

Al no obtener una respuesta satisfactoria de parte del general Bulnes, y debido a que los elogios y buenos oficios de Santa Cruz podían no ser suficientes, O'Higgins apeló a otros argumentos que podían disuadir a Bulnes en su empresa. El general recurrió entonces a los problemas con que se iba a enfrentar el ejército en tierras peruanas, siendo estos, justamente, una de las razones del fracaso de la primera expedición al mando de Manuel Blanco Encalada. En seis meses, advierte O'Higgins, el bravo soldado chileno iba a tener que luchar contra la fiebre, disentería y males de hígado50.

A raíz de esta y otras evidencias similares, O’Higgins instaba a Bulnes a consultar con las máximas autoridades si tenía sentido continuar una campaña que podía traer un pésimo resultado para las huestes chilenas.

Fracasados los argumentos personales y militares, O’Higgins buscó la justificación racional para tratar de convencer a Bulnes de que no tenía sentido emprender una guerra contra la Confederación. En una larga carta, escrita a inicios de diciembre de 1838, intentaba demostrar que la oposición de Chile a la unión de Perú y Bolivia no tenía justificación alguna. El gobierno de Chile, a juicio de O’Higgins, se había formado una opinión errada contra la Confederación y no correspondía buscar su destrucción, tal como explicaba con el siguiente ejemplo:

Si el Gobierno de Chile se justificare hacer una guerra con el fin de disolver la unión entre el Alto y Bajo Perú, el gobierno de Perú se justificaría de igual modo en hacer la guerra para disolver la unión entre el archipiélago de Chiloé y la República de Chile, y, en apariencia, con alguna razón, porque el Archipiélago de Chiloé estaba gobernado por el Perú, cuando éste nunca lo fue por Chile51.

\footnotetext{
${ }^{48}$ Carta de Bernardo O'Higgins a Andrés de Santa Cruz, Lima, 10 de noviembre de 1838. Epistolario, II, 241242. Archivo de don Bernardo O'Higgins, XXXII, 261-262, Ibidem, Tomo III, pp. 211-212.

${ }^{49}$ Carta de Bernardo O'Higgins a Andrés de Santa Cruz, Lima, 10 de noviembre de 1838. Epistolario, II, 241242. Archivo de don Bernardo O'Higgins, XXXII, 261-262, Idem.

${ }^{50}$ Carta de Bernardo O'Higgins a Manuel Bulnes, Lima, 13 de noviembre de 1838. Epistolario, II, 244-245. Archivo de don Bernardo O'Higgins, XXXII, 263-264, Ibidem, Tomo 1, pp. 156-157.

${ }^{51}$ Carta de Bernardo O'Higgins a Manuel Bulnes, Lima, 15 de diciembre de 1838. Epistolario, II, 248-251. Archivo de don Bernardo O'Higgins, XXXII, 277-280, Ibidem, Tomo 1, pp. 157-159.
} 
Algo similar, insistía, se podría dar respecto al Estado Araucano y demás naciones indígenas. Perú podría atribuirse el mismo derecho que exigía Chile y oponerse a su unión con el Estado chileno.

Luego de esta ilustrativa aclaración, O’Higgins insistía en otras razones a favor de la paz y la buena relación entre los pueblos, esperanzado de que por medio de estas líneas sería capaz de frenar la marcha de la guerra.

\section{El general Prieto y el ministro Portales}

Entre las cartas que se conservan dirigidas al Presidente José Joaquín Prieto, queda claro que Bernardo O'Higgins buscaba ocupar su prestigio para interceder por el gobierno peruano, en este caso específico, por Agustín Gamarra y por el inicio de las tensiones entre ambos gobiernos en la guerra de impuestos por el trigo y azúcar a la que hacíamos mención anteriormente.

Más que al presidente chileno, las críticas apuntaban a Diego Portales. El hecho de que el Ministro no hubiera participado en las Guerras de Independencia fue un tema recurrente entre los oficiales chilenos ${ }^{52}$. La crítica, en conjunto con el desprecio, se fue acentuando en la medida que Portales fue adquiriendo cada vez más poder dentro del Gobierno y haciéndose cargo de temas relacionados con el mundo militar ${ }^{53}$.

Esto queda en evidencia cuando Bernardo O'Higgins, se comunicó con el general San Martín, para criticar al Gobierno chileno por no cumplir con las deudas pendientes, como sí lo había hecho Perú. La responsabilidad radicaba, según él, en el presidente Prieto por subordinarse al sector liderado por Portales y entregarse a los enemigos de la patria: «gavilla de corrompidos que tanto mal ha hecho, no solamente a Chile, sino a la causa

\footnotetext{
${ }^{52}$ Sobre la relación entre Portales y el Ejército recomendamos el trabajo de Vergara, Sergio, «Portales y el Ejército», en Bravo Lira, Bernardino (compilador), Portales, el hombre y su obra: La consolidación del gobierno civil, Editorial Jurídica de Chile, Santiago, 1989 (pp. 87-116).

${ }^{53} \mathrm{El}$ acta de los oficiales que se sublevaron contra el Gobierno en Quillota, destacan en su declaración este hecho, apuntando obviamente al Ministro Portales: «En la ciudad de Quillota, cantón principal del ejército expedicionario sobre el Perú, a tras de Junio de 1837 años, reunidos, espontáneamente los jefes y oficiales infrascritos, con el objeto de acordar medidas oportunas para salvar a la patria de la ruina y precipicio a que ella se halla expuesta por el despotismo absoluto de un solo hombre, que ha sacrificado constantemente a su capricho la libertad y la tranquilidad de nuestro amado país, sobreponiéndose a la Constitución y a las leyes, despreciando los principios eternos de justicia, que forman la felicidad de las naciones libres, y finalmente, persiguiendo cruelmente a los hombres más beneméritos que se han sacrificado por la independencia política. (... )", Copia del Acta de los sublevados del motín de Quillota, Valparaíso, 13 de junio de 1837, Archivo Nacional, Fondo Ministerio de Guerra, vol. 247, fojas 71 y 72.
} 
común de América. Su administración, concluye O’Higgins, me ha sido más enemiga y contraria que alguna otra de las anteriores» ${ }^{54}$.

Un año después, reitera este punto, atribuía los errores del Presidente a no rodearse de la gente adecuada y a su falta de experiencia política: «aunque es un antiguo soldado, es solo un joven político» ${ }^{55}$.

La animadversión a Portales se incrementó, luego de la expedición de Ramón Freire y poco antes que se oficializara la declaración de guerra. Si esta se llevaba a cabo, ambos países sufrirían gravísimos males, sin embargo: «Se opina que el mismo Portales no se conforma con nada, porque habiéndose dispuesto para la guerra, teme su caída en la paz» ${ }^{56}$. Se trata, sin un lugar a dudas de una opinión interesante que reafirma, como se ha visto en otros estudios, que la guerra externa beneficiaba el orden político y la estabilidad interna de un régimen que se había impuesto a la fuerza posterior al triunfo contra los liberales en Lircay ${ }^{57}$.

En esta misma misiva, O’Higgins frente al otro gestor de la independencia de Chile y Perú, volvía a denostar a Portales por el hecho de haber querido dirigir los destinos de la patria, sin haber hecho los méritos durante las guerras de independencia:

A los que nada les ha costado y quieren elevarse sobre la ruina de los que se sacrificaron por su caro suelo, poco les importa el honor nacional, la prosperidad de la América y la pública tranquilidad, porque no teniendo título para gobernar y dar anchura a sus aspiraciones, quieren por la fuerza sobreponerse a la razón y a la justicias ${ }^{58}$.

\footnotetext{
${ }^{54}$ Carta de Bernardo O’Higgins a José de San Martín, Lima, 27 de mayo de 1836. Epistolario, II, 195-199, Cartas de O'Higgins..., op. cit., Tomo III, p. 194.

${ }_{55}$ Carta de Bernardo O'Higgins a Miguel Zañartu, Sin fecha ni lugar (1838). Epistolario, II, 238-239, Ibidem, Tomo III, pp. 283-284.

${ }^{56}$ Carta de Bernardo O’Higgins a José de San Martín, Lima, 20 de diciembre de 1836. Epistolario, II, 203206, Ibidem, Tomo III, pp. 198-199.

57 Núñez, Jorge, «Estado, Crisis de hegemonía y Guerra en Chile (1830-1841) », Andes, n6, 1987 (pp. 137189).

${ }^{58}$ Carta de Bernardo O'Higgins a José de San Martín, Lima, 20 de diciembre de 1836. Epistolario, II, 203206, Cartas de O'Higgins..., op. cit., Tomo III, pp. 198-199.
} 
Portales, acusaba el general O'Higgins en otra carta dirigida al mariscal Santa Cruz, invertía los fondos de Chile en una guerra tan despiadada como injusta ${ }^{59}$. Después de haber luchado tantos años en favor de la independencia y haber arriesgado la vida en pos de esta causa, la posibilidad de ver a ambos países enfrentados lo horrorizaba y era causa de un profundo desánimo en el general O'Higgins ${ }^{60}$.

No satisfecho con despreciar al Ministro, su estrategia apuntó luego a desacreditar la popularidad de la guerra y la campaña. En otra carta dirigida a Santa Cruz, cuando este ocupaba el rol de «Supremo Protector de la Confederación Perú Boliviana», expone las carencias de la expedición organizada por Portales y la falta de apoyo, como se lee a continuación:

Habrá Ud., mi querido General, oído cartas y rumores venidos por varios buques de Valparaíso y Talcahuano. Casi todos convienen más o menos, en la situación desesperada en que se encuentra don Diego Portales en su loca y temeraria empresa; la falta de elementos de guerra y la pobreza han desconcertado su razón hasta intentar un empréstito forzoso de los extranjeros quienes se han negado decididamente. Hombres viejos de setenta, algunos muchachos lánguidos de 14 años, todos cubiertos de andrajos, son los adornos de su campamento de las Tablas ${ }^{61}$.

Al juicio crítico sobre el Ministro, se agregan una serie de detalles de la composición de la fuerza entregados al mariscal que dan para dudar de qué lado estaba realmente O’Higgins en esta guerra. En definitiva, y más allá del patriotismo que se vanagloriaba de destacar en otras cartas, el general no hacía más que entregar información útil al rival de Chile en la guerra, apostando, seguramente, al fracaso de la Expedición y a un triunfo confederado.

Asimismo, queda la sensación de que O’Higgins manejaba información clave sobre el destino de Portales. Citando a un extranjero, señalaba: «poco tiempo más de firmeza por

\footnotetext{
59 Carta de Bernardo O'Higgins a Andrés de Santa Cruz, Hacienda de Montalván, 20 de mayo 1837. Archivo de don Bernardo O'Higgins, XXXII, 216-218, Ibidem, Tomo III, pp. 207-208.

60 Destinatario no identificado, Lima, 24 de agosto de 1836. Archivo de don Bernardo O'Higgins XXXII, 194196, Ibidem, Tomo III, p. 300.

${ }^{61}$ Carta de Bernardo O'Higgins a Andrés de Santa Cruz, Callao, 12 de marzo de 1837. Epistolario, II, $210-212$. Archivo de don Bernardo O'Higgins, XXXII, 209-211, Ibidem, Tomo III, pp. 205-206.
} 
parte de Perú para que el enemigo de la paz perezca de consunción por su propia debilidad» y agregaba, más adelante, una frase inquietante respecto del presidente Prieto: «Podemos esperar que la misma mano providencial que obstruye las sendas del mal, quite la venda de los ojos de Prieto para que vea la luz que le deseamos» ${ }^{62}$.

A raíz de esto insiste con señalar al general Prieto que quienes impulsaban la guerra, refiriéndose de forma tácita a Portales, no buscaban más que el beneficio personal, como se puede leer a continuación: «En todos los países hay siempre un número de personas que desean la guerra con la esperanza de convertir semejante acontecimiento en lucros y provechos propios 63 , por lo que debe haber mucho cuidado en no oír a estos especuladores» 64 .

El crimen de Portales, perpetrado por un grupo de oficiales que se revelaron por las mismas razones que aludía O'Higgins contra la guerra, hizo suponer al prócer de la independencia que se generaría un cambio en la postura del Gobierno contra la Confederación. Mediante una carta, Bernardo O'Higgins informó a José de San Martín de la muerte de Portales: «está bajo tierra», le señalaba. Los lamentables acontecimientos, especulaba el general, parecían conducentes a una paz permanente y el Gobierno estaría en «la precisa y necesaria medida de adoptar y aceptar la paz, que últimamente le ha ofrecido, de muy buena fe, el general Santa Cruz» 65 .

A diferencia de lo que se puede percibir en las cartas de Santa Cruz ${ }^{66}$, relativas a la muerte del Ministro, llama la atención la confianza que tiene O’Higgins respecto a que su asesinato significaría el fin de la guerra y permite especular, contrario a lo que ha planteó

${ }^{62}$ Carta de Bernardo O’Higgins a Andrés de Santa Cruz, Callao, 12 de marzo de 1837. Epistolario, II, 210-212. Archivo de don Bernardo O'Higgins, XXXII, 209-211, Idem.

${ }^{63}$ Tiempo después insistiría en que «el desgraciado Portales», enceguecido por la rueda de la ciega fortuna buscaba, a través de esta guerra, tener la oportunidad favorable para adquirir su dictadura perpetua. Carta de Bernardo O'Higgins a Manuel Bulnes, Sin lugar, 10 de enero de 1839. Archivo de don Bernardo O'Higgins, XXXII, 292-293, Ibidem, Tomo I, p. 159.

${ }^{64}$ Carta de Bernardo O’Higgins a José Joaquín Prieto, Lima, 29 de diciembre de 1836. Epistolario, II, 206210. Archivo de don Bernardo O'Higgins, XXXII, 196-200, Ibidem, Tomo II, pp. 293-296. Sobre este punto es interesante revisar el artículo de Jorge Núñez. El historiador reduce a dos factores el impulso de la guerra por el núcleo ultra conservador portaliano: la crisis política y el inminente cierre del mercado peruano. Núñez, Jorge, op. cit., pp. 137-189.

65 Carta de Bernardo O'Higgins a José de San Martín, Lima, 23 de agosto de 1837. Epistolario, II, 214-218, Cartas de O'Higgins..., op. cit., Tomo II, pp. 200-202.

${ }^{66}$ «La muerte de Portales y el estado de desorden que debemos suponer en Chile no han de inspirarnos funesta confianza. Si Prieto logra sostenerse algunos meses, puede ser que uno de los últimos esfuerzos de desesperación que haga para prolongar su existencia política sea alejar de sus costas un ejército emponzoñado por el espíritu de rebeldía y enviarlo a Perú, aunque sea con la certeza de un mal éxito", Carta de Andrés de Santa Cruz a Domingo Nieto, Lima, 8 de agosto de 1837, en Mc Evoy, Carmen y Rénique, José Luis, op. cit., p. 558. 
la prensa de la época para atizar el conflicto, que era O'Higgins y no Santa Cruz quien parecía estar más cerca de la revolución de Quillota.

Esto explicaría, además, su desilusión cuando el crimen no evita la guerra y la expedición siguió su curso, como queda de manifiesto en una carta que escribió al general Santa Cruz a fines de 1837 desde su hacienda de Montalván:

Vine en principios de octubre último a atender los trabajos de esta hacienda, considerando que separado el finado Portales del teatro de sus gestiones prohibidas, no habría agresión por parte de sus sucesores, porque creía que ellos tendrían luces suficientes para hacer ver las locuras y errores de ese desdichado (...) pero la ambición, que debe llamarse el peor de todos los vicios, arrojó a ese club incorregible a perpetrar todo lo maligno y prohibido67.

Una vez que O’Higgins perdió la esperanza de que el crimen de Portales terminaría con esta ambiciosa empresa, dirigió todas sus críticas al Presidente:

Prieto, sordo a mis consejos y ciego por la ignorancia y la pasión, ha cometido el acto más criminal, permitiendo el sacrificio de un puñado de hombres, víctimas evidentes del infernal capricho del círculo corrompido que lo gobierna como un fantoche. Es un hombre perdido para siempre, pues ninguna persona honrada podrá ser en adelante amigo de un individuo tan estúpido como insensato $^{68}$.

\footnotetext{
${ }^{67}$ Carta de Bernardo O'Higgins a Andrés de Santa Cruz, Hacienda de Montalván, 1 de diciembre de 1837. Archivo de don Bernardo O'Higgins XXXII, 229-231, Cartas de O'Higgins..., op. cit., Tomo III, pp. 208- 209. ${ }^{68}$ Carta de Bernardo O'Higgins a Juan Thomas, Montalván, 10 de octubre de 1837. Epistolario, II, 220-221. Archivo de don Bernardo O'Higgins XXXII, 222-223, Ibidem, Tomo III, p. 241.
} 
Ya viviendo los efectos de la guerra, en específico, la invasión de la primera expedición al mando del almirante Blanco Encalada, mantenía su frustración y trato despectivo hacia el presidente:

No creí que Prieto hubiera tocado el último grado de insanía, al permitir salir de los puertos de Chile la invasión de 13 buques que se anuncia asomaron en Arica, tres de los cuales fueron rechazados al aproximarse a las baterías. Prieto es perdido para siempre, sea cual fuese el éxito de los invasores que, en mi opinión, sucumben tarde o temprano ${ }^{69}$.

\section{El general Bulnes y la victoria de Yungay}

Las cartas del general José María de la Cruz son un documento de inestimable valor para tener una imagen un poco más completa y humana del Capitán General en Perú. Su permanencia en la casa de O'Higgins mientras estuvo enfermo, le permitieron completar un cuadro que entregó nuevas luces sobre él y su relación con Bulnes. Según estos recuerdos, el general Bulnes se complacía con las visitas a Bernardo O’Higgins:

Debo a éste viejecito7o el no haberme vuelto tal vez loco en los momentos de conflicto en que, casi diariamente, me colocan las ocurrencias. Yo no conocía la importancia personal de este buen chileno, si no ahora que las circunstancias me han acercado a él. Antes de tratarle con intimidad tenia desesperación, más hoy he adoptado como un recurso de desahogo visitarle, porque tiene sagacidad y claridad para explanar y desenvolver las ocurrencias que pueden conducir los sucesos, que cuando me retiro a casa, no sólo me hallo desembarazado y en calma, sino también lleno de una confianza satisfactoria ${ }^{71}$.

\footnotetext{
${ }^{69}$ Carta de Bernardo O’Higgins a Rosa O'Higgins, Montalván, 7 de octubre de 1837. Epistolario, II, 219-220, Ibidem, Tomo II, p. 131.

70 Bernardo O'Higgins tenía sesenta años en 1838 y Bulnes estaba próximo a cumplir los cuarenta.

${ }^{71}$ Carta de José María de la Cruz a Diego Barros Arana, Queime, mayo 22 de 1855. De la Cruz, José María, op. cit., p. 142.
} 
Consecuente con esto, O'Higgins habría sido clave en pronosticar un triunfo del ejército chileno sobre la Confederación, después de haber derrotado al mejor batallón y regimiento de caballería en Guías ${ }^{72}$, poco antes de la victoria en Yungay.

Al poco tiempo de haberse enterado de la victoria, se produjo un intercambio epistolar entre Bulnes y O'Higgins. El primero aseguraba que intentó hasta el mismo día de la batalla negociar la paz con el general Santa Cruz, pero que esto fue imposible 73 . La respuesta del prócer de la independencia se centró en destacar el valor heroico que su «invencible» ejército ostentó en ese día memorable, elogios que surgían a partir de los testimonios que recibió O'Higgins de quienes habían sido sus oponentes ${ }^{74}$.

Si las últimas cartas de las que se tenga registro fueron enviadas al general Prieto para disuadirlo de llevar a cabo la guerra contra la Confederación y en otras anexas dispensó un trato despectivo hacia el general, tratándolo de imbécil, estúpido e insensato, en la última epístola que se tenga registro dirigida al mandatario, uno se encuentra con una serie de elogios, en los que parece haber olvidado la serie de descalificaciones que prodigó a Prieto:

La victoria de Yungay vuelve a poner la pluma en mis manos, no para distraerlo de sus graves atenciones, sino para felicitarlo por un triunfo en que nuestra querida patria ha obtenido todo cuanto podia desear, su honor, su seguridad y la independencia del Perú, por lo que Chile ha hecho tan generosos sacrificios ${ }^{75}$.

Atrás quedaba la defensa del general Santa Cruz, la búsqueda de buenos oficios por parte de Gran Bretaña y la ácida crítica a una guerra que se consideraba un capricho de Portales. De un momento a otro, el general pareciera haber abandonado sus principios, olvidado sus lamentos por el enfrentamiento de dos pueblos hermanos, para pasar por alto

72 «Un batallón de tiradores y dos o tres columnas mandadas a cargar a tiempo con decisión, le darán a V. la victoria, porque al soldado peruano le falta ese ardor y energía individual que caracteriza al chileno». Carta de José María de la Cruz a Diego Barros Arana, Queime, mayo 22 de 1855. Ibidem, p. 143.

73 Carta de Manuel Bulnes a Bernardo O'Higgins, Huaraz, 27 de enero de 1839. Bulnes, Gonzalo, Historia de la campaña de Perú de 1838, Imprenta de Los Tiempos, Santiago, 1878, pp. 404 - 405.

${ }^{74}$ Carta de Bernardo O'Higgins a Manuel Bulnes, Sin lugar, 26 de febrero de 1839. Archivo de don Bernardo O'Higgins XXXII, 304-305, Cartas de O'Higgins..., op. cit., Tomo I, p. 161.

75 Carta de Bernardo O'Higgins a José Joaquín Prieto, Lima, 5 de marzo de 1837. Epistolario, II, 272. Archivo de don Bernardo O'Higgins, XXXII, 305-306, Ibidem, Tomo II, p. 298. 
el mar de sangre que quedó tras Yungay con casi tres mil soldados muertos: 1.400 de la Confederación y 1.300 del Ejército Restaurador ${ }^{76}$ y de los que ya nadie se parecía acordar. Por el contrario, no sabemos si de forma sincera o no, O’Higgins destacó la relevancia que tuvo la victoria para la construcción de la nación:

Los ilustres nombres de Bulnes y Cruz serán siempre dos columnas poderosas en que descanse la República de Chile, porque es evidente que los baluartes más firmes del poder nacional son la gloria nacional, los hechos de sus hijos y las hazañas de sus héroes, glorias que ahora enlazan de nuevo a pueblos hermanos, y glorias que serán siempre vivas a la sombra de una paz perpetua, que ha sido desde el principio, y ahora más que nunca, mi constante ruego al Todopoderoso 77 .

Consciente de su condición de héroe, O’Higgins veía cómo ahora iba a tener que compartir el panteón junto al general Manuel Bulnes y, quizás, José María de la Cruz. No obstante, los hechos evidencian más que una postura acomodaticia al resultado de la guerra. La presencia de Bulnes en Perú, sus charlas y reuniones ${ }^{78}$, debieron haber sido determinantes en el cambio de mirada, en especial, cuando ya no estaba la figura de Portales detrás del conflicto.

Una vez que Chile consiguió la victoria, según el relato del historiador Gonzalo Bulnes, el presidente Prieto ofreció a su padre, Manuel Bulnes, que solicitara algo en reconocimiento a su labor. El general Bulnes se habría contentado en pedir la reincorporación de los oficiales dados de baja por la revolución de 1830 y que se le devolviesen los títulos y honores a Bernardo O'Higgins ${ }^{79}$. Una acción que explicaría la

\footnotetext{
${ }^{76}$ Las cifras, estimativas aparecen mencionadas en Bulnes, Gonzalo, op. cit., pp. 399 - 400.

77 Carta de Bernardo O’Higgins a José Joaquín Prieto, Lima, 5 de marzo de 1837. Epistolario, II, 272. Archivo de don Bernardo O'Higgins, XXXII, 305-306, Cartas de O'Higgins..., op. cit., Tomo II, p. 298.

${ }^{78}$ Ante la posibilidad de recibir la visita de Bulnes en la Hacienda de Montalván, O'Higgins dio instrucciones a uno de sus empleados para que preparan el lugar, limpiándolo, pintándolo, reparando algunas cosas, como la escalera y preocuparse por tener una buena cantidad de comida, con este fin encarga tres o cuatro pavos, una docena de gallinas, media docena de patos chicos y media docena de pollos. Carta de Bernardo O'Higgins a José Toribio Pequeño, Lima, 29 de abril de 1839. Epistolario, II, 275-276. Archivo de don Bernardo O'Higgins, XXXII, 313-315, Ibidem, Tomo II, pp. 194-195. Más adelante se preocupará de comprar cervezas y vinos europeos para recibir al general. Carta de Bernardo O'Higgins a José Toribio Pequeño, Lima, 10 de junio de 1839. Archivo de don Bernardo O'Higgins, XXXII, 324-327, Ibidem, Tomo II, pp. 200-201. 79 Bulnes, Gonzalo, op. cit., p. 415.
} 
estrecha relación que se generó entre ambos en Perú y el apoyo del prócer a la empresa chilena, la misma que antes había criticado.

Durante el mes de agosto de 1839, el general recibió la feliz noticia de que el Gobierno y el Congreso habían decidió restituir su grado y los beneficios que este implicaba. En una sentida carta al Ministro, señalaba:

He tenido el honor de recibir la distinguida comunicación de V.S. 8 de Agosto ultimo en la que me transcribe de Suprema orden haver tenido abien S. E. el Presidente de la República con igual fecha, decretar con la aprobacion unanime de la Cámara de los Senadores quedar yo restituido a mi empleo de Capitan Gral. de Ejto. de Chile con la antigüedad correspondiente a mi primitivo nombramiento, seame permitido, por Usted, al tribunal mi reconocimiento por este acto de Justicia verdaderamente Nacional significar a V.S. intimamente penetrado del valor propio de este asunto, que siempre espere tranquilo seme hiciera justicia (...) nunca he desmerico de mi Patria y que en todas epocas y vicisitudes, mi espiritu y corason han visto y veran el pais de nacimiento, por cuya libertad he hecho cuantos servicios han estado en mis alcances y los hare siempre suspirando por la felicidad80.

Fue en este contexto que O'Higgins se esmeró ante la posibilidad de volver a recibir al general Bulnes, siendo este un tema recurrente en las cartas a Pequeño. No obstante, esto no ocurrió y en el mes de octubre de 1839, O’Higgins anunció la partida de la división chilena rumbo al sur ${ }^{81}$.

El resto de las cartas están relacionadas con recomendaciones ${ }^{82}$, con restitución de su empleo y la posibilidad de regresar a Chile, tema que provocó una profunda alegría en

${ }^{80}$ Carta de Bernardo O’Higgins, al Señor Ministro de Guerra y Marina don Ramón Cabareda, Lima 4 de octubre de 1839, Archivo Nacional de Chile, Fondo Ministerio de Guerra, vol. 231.

${ }^{81}$ Liberado de la visita, el general anunciaba a su compadre: «Habiendo dado la vela el Callao para Talcahuano el general Bulnes con sus tropas el 19 del corriente, me encuentro libre para dar un paseo por esta hacienda». Carta de Bernardo O'Higgins a José Toribio Pequeño, Lima, 21 de octubre de 1839. Archivo de don Bernardo O'Higgins, XXXII, 351, Cartas de O'Higgins... , op. cit., Tomo II, p. 220.

${ }^{82}$ Recomendación del general Pío Tristán para que fuese recibido en Chile. Carta de Bernardo O'Higgins a Manuel Bulnes, Lima, 4 de enero de 1840. Archivo de don Bernardo O'Higgins, XXXII, 357-358, Ibidem, Tomo I, p. 160; Recomendación a José Borne para obtener un trabajo en Chile. Carta de Bernardo 
el general, tal como puede deducirse de sus cartas ${ }^{83}$, en contraposición a la desilusión que generó no poder efectuar este retorno debido a razones de salud.

El epistolario de los últimos años deja entrever el interés del general por tratar de limpiar su imagen, ya pensando más en cómo iba a pasar a la historia que en seguir activo en la política: «El porvenir demostrará al mundo si he obrado bien o mal» ${ }^{84}$. Así también se deduce de una carta escrita a Miguel de la Barra, donde deseaba justificar, a través de razones ocultas, los motivos que lo llevaron a renunciar al cargo en $1823^{85}$.

Finalmente, las últimas cartas de O’Higgins versan sobre su estado de salud, una preocupación constante por la situación de los indios del sur ${ }^{86} \mathrm{y}$, finalmente, por una compensación económica de parte del Gobierno debido a los perjuicios económicos sufridos y donaciones efectuadas durante la época de la independencia, con el fin de que la restitución de estos bienes fueran en beneficio de la Sociedad de Agricultura de Santiago ${ }^{87}$. Su experiencia comercial en la producción y venta de azúcar Perú lo había

O'Higgins a José Borne, Lima, 25 de marzo de 1839. Archivo de don Bernardo O'Higgins, XXXII, 309-310, Ibidem, Tomo I, pp. 152-153.

${ }^{83}$ José María de la Cruz recordaba la enorme alegría que le provocaba imaginar a O'Higgins regresar a Chile: «Está, pues, en el orden, regrese al seno de mis compatriotas, que son mi familia, mis hijos, mis hermanos, mis antiguos amigos. Los quiero ver, saludar, y abrazar a todos sin excepción». Carta a José María de la Cruz, Lima, 10 de diciembre de 1841. Archivo de don Bernardo O'Higgins, XXXII, 455-459, Ibidem, Tomo I, pp. 217-220.

${ }^{84}$ Carta a José María de la Cruz, Lima, 10 de diciembre de 1841. Archivo de don Bernardo O’Higgins, XXXII, 455-459, Idem.

85 «El mundo está en ignorancia total hasta ahora y probablemente continuará así hasta que yo baje al sepulcro, principalmente con respecto a las causas de los movimientos revolucionarios que tuvieron lugar en Chile en diciembre de 1822 y enero de 1823 , como de mi determinación de ceder el destino de Director Supremo (...) Estos son secretos que probablemente durante mi vida no sean sabidos, y mientras el mundo permanezca sin conocerlos estará sujeto a ser engañado por gruesas calumnias, artificiosas y falsas representaciones». Carta de Bernardo O'Higgins a Miguel de la Barra, Su casa, 5 de junio de 1839. Archivo de don Bernardo O'Higgins, XXXII, 322-324, Ibidem, Tomo I, p. 117.

${ }^{86}$ Este tema ya aparece mencionado en una carta al Presidente de los Estados Unidos, Martín Van Buren, 29 de julio de 1838, en la que hace refrencia a la buena relación que tenía su padre Ambrosio O’Higgins con los araucanos para que sirviera de ejemplo a la situación que vivía Estados Unidos con sus aborígenes. Carta de Bernardo O'Higgins a Martin van Buren. Archivo de don Bernardo O'Higgins, XXXII, 253-257, Ibidem, Tomo I, pp. 169-171. Este tema vuelve a ser reflotado más adelante, primero en un reconocimiento a la labor desempeñada por José María de la Cruz y luego en recomendaciones a Manuel Bulnes, cuando ya había asumido el cargo de Presidente: Carta a José María de la Cruz, Montalván, 5 de abril de 1840. Epistolario, II, 286-291. Archivo de don Bernardo O'Higgins, XXXII, 366-371, Ibidem, Tomo II, pp. 213-216; Carta de Bernardo O'Higgins a Manuel Bulnes, Lima, 4 de agosto de 1842. Archivo de don Bernardo O'Higgins, XXXII, 489-491, Ibidem, Tomo I, pp. 164-165 y Carta de Bernardo O'Higgins a Manuel Bulnes, Callao, 21 de julio de 1842. Archivo de don Bernardo O'Higgins, XXXII, 485-487, Ibidem, Tomo I, pp. 161-162. 87 Carta de Bernardo O'Higgins a Manuel Bulnes, Lima, 17 de octubre de 1842. Archivo de don Bernardo O’Higgins, XXXII, 495-498, Ibidem, Tomo I, pp. 166-168. 
convencido de que la agricultura era uno de los medios para lograr el desarrollo económico de una República.

\section{Conclusiones}

La imagen de O’Higgins retirado en el campo, luego de su renuncia en 1823, aparece a ojos de sus defensores como la del general romano Lucio Quincio Cincinato, símbolo de rectitud y honradez. Desde Perú, el general rechazaba los honores y velaba por la paz americana, sin ningún otro interés que el progreso de Chile.

Una mirada que contrasta con la de un héroe desterrado y despreciado al punto que, para poder subsistir, debió dejar la espada y obtener del campo los recursos que le permitían mantenerse. El trance en Perú se sobrellevaba avocándose de lleno a la producción y venta de azúcar, por la que llegó transformarse en respetado hacendado del norte.

En esta misma línea, a Bernardo O'Higgins, la posibilidad de que Chile y Perú se vieran envueltos en una guerra le afectaba porque, como dice en sus cartas, no luchó por su independencia para que luego se derramara la sangre entre hermanos, pero también por sus propios intereses, el negocio del azúcar que, como hemos visto, se vía amenazado por el conflicto e inestabilidad.

Más que la guerra en sí misma, y más allá de los buenos sentimientos en contra de ella, tal como queda evidenciado en sus cartas, O’Higgins luchaba contra la anarquía y el desorden a que este tipo de enfrentamientos podía llevar. Más que un modelo, como el de la Confederación; un líder, que podía ser Luis José Orbegoso, Andrés de Santa Cruz o José Joaquín Prieto, lo que le preocupaba era el establecimiento de un sistema y liderazgo en el que se aseguraran las condiciones de estabilidad política y comercial para poder funcionar.

$\mathrm{Su}$ relación con el general Prieto merece un párrafo aparte. Después de varios intentos por convencer a Prieto de que las buenas intenciones de Santa Cruz y su Confederación y los perjuicios que conllevaría un enfrentamiento, O’Higgins muestra su lado más oscuro al vilipendiar al Presidente tratándolo de ciego, sordo, estúpido e insensato. Su postura cambió radicalmente luego de la victoria, en especial, por la restitución de los grados y los vientos de cambio que venían en Chile. El general O’Higgins, seguramente, intuía o ya estaba proyectado la llegada de Bulnes a la presidencia.

Respecto a Diego Portales, queda en evidencia la animadversión que le provocaba este personaje a O'Higgins, un aparecido que no tenía el prestigio suficiente para ser parte del Gobierno en Chile. Portales representa todos los males y errores que comete el Gobierno. 
Esta obcecación con el Ministro y la fe en que estando bajo tierra iban a acabar todos los males, avalan la posibilidad de que haya sido participe o por lo menos haya avalado el motín de Quillota. Las razones de los sublevados en contra la guerra y de Portales coinciden con las del general O'Higgins.

Los elogios a Manuel Bulnes y José María de la Cruz, después de la victoria de Yungay, donde se perdieron miles de vidas de pueblos hermanos, contrasta con las buenas intenciones antes de la lucha y reflejan, a nuestro juicio, a un hombre pragmático que entendía, como lo estuvo en algún momento a favor de Santa Cruz y la Confederación, que ya estaba demasiado viejo para sacrificar sus intereses particulares en detrimento de sus ideales.

¿Esto minimiza la figura heroica que algunos han intentado construir sobre O'Higgins? No, lo humaniza. Lo baja del pedestal y lo transforma en un hombre de carne y hueso, tal como ocurre con Diego Portales y muchos otros. El error de los historiadores de mediados del siglo XX estuvo en creer que mezclar intereses, político y económicos, los hacía menos patriotas. 


\section{Bibliografía}

\section{Fuentes Primarias:}

- Archivo Nacional de Chile, Fondo Ministerio de Guerra, Vol. 231.

- $\quad$ el araucano, 5 de febrero de 1836.

- Epistolario de Diego Portales, edición a cargo de Carmen Fariña, Ediciones Universidad Diego Portales, Santiago, 2007, Tomos I y II.

- Copia del Acta de los sublevados del motín de Quillota, Valparaíso, 13 de junio de 1837, Archivo Nacional, Fondo Ministerio de Guerra, Vol. 247, Fojas 71 y 72 .

- O’Higgins, Bernardo, Cartas de Bernardo O'Higgins, Guerrero, Cristián y Miño, Nancy (editores), editorial Historia Chilena, Santiago, 2011.

\section{Fuentes Secundarias:}

- AmunÁtegui, Miguel Luis y Vicuña Mackenna, Benjamín, Vida del General don Bernardo O'Higgins (Su Dictadura Su Ostracismo), Editorial Rafael Jover, Santiago, 1882.

- Basadre, Jorge, Historia de la República del Perú, Editorial Panamericana, Lima, 1963, Tomo I.

- Bello, Juan, Don Bernardo O'Higgins, Galería Nacional y Colección de Biografias y Retratos de Hombres Célebres de Chile, dirigida y publicada por Narciso Desmadryl, Santiago, 1854, pp. 70 107.

- Bonilla, Heraclio en Bethell, Leslie, Historia de América Latina, Vol. 6, Editorial Crítica, Barcelona, 1991.

- Bulnes, Gonzalo, Historia de la campaña de Perú de 1838, Imprenta de Los Tiempos, Santiago, 1878.

- Campos Harriet, Fernando, La vida heroica de O'Higgins, Esc. Tip. La Gratitud Nacional, Santiago, 1947

- Campos Méndez, Enrique, Bernardo O'Higgins. El Padre de la Patria, Editorial EMECÉ, Buenos Aires, 1942.

- Cariola, Carmen y Sunkel, Osvaldo, Un siglo de Historia Económica de Chile 1830 1930, Editorial Universitaria, Santiago, 1990. 
- Cavieres, Eduardo y Serrano, Gonzalo, «La guerra de Chile contra la Confederación Perú Boliviana (1836 1839): el trigo y la agricultura como bases de un proyecto nacional», Revista América Latina en Historia Económica, Vol. 25, Núm. 1, pp. 136 y 164.

- Clavel, Roberto, «Una biografía de Bernardo O’Higgins Riquelme», en Varios autores, Bernardo O'Higgins: Retrospectiva histórica y herencia del padre de la Patria, Universidad Bernardo O’Higgins, Santiago, 2009, pp. 9 50.

- De la Cruz, José María, Recuerdos de Don Bernardo O'Higgins, Introducción y notas de Jaime Eyzaguirre, Editorial Andrés Bello, Santiago, 1960.

- $\quad$ Eyzaguirre, Jaime, O’Higgins, Zigzag, Santiago, 1950.

- Fernández, Sergio, O’Higgins, Editorial Orbe, Santiago, 1974.

- GAY, Claudio, La agricultura chilena, Cámara Chilena de la Construcción, PUCCH, DIBAM, I, Santiago, 2009.

- Gottenberg, Paul, Caudillos y comerciantes, Centro de Estudios Regionales Andinos «Bartolomé de Las Casas», Perú, 1997.

- Izquierdo, Gonzalo, Historia de Chile, Editorial Andrés Bello, Santiago, 1990, Tomo II.

- Mc Evor, Carmen y Rénieue, José Luis, Soldados de las República. Guerra y correspondencia y memoria en el Perú (1830 1844), Fondo Editorial del Congreso del Perú e Instituto Riva Agüero, Lima, 2010.

- Monroy, Gustavo, La Confederación Perú Boliviana, Fondo Editorial Universidad de Ciencias y Humanidades, Lima, 2013.

- NúÑEZ, Jorge, «Estado, Crisis de hegemonía y Guerra en Chile (1830 1841) », Andes, $\mathrm{N}^{\circ}$ 6, Santiago, 1987, pp. 137 189.

- Parkerson, Phillip, Andrés de Santa Cruz y la Confederación Perú-boliviana 1835 1839, Librería Editorial Juventud, La Paz, 1984.

- PINTO, Julio, «¿La tendencia de la masa al reposo? El Régimen portaliano enfrenta al mundo plebeyo, 1830 1851», Revista Historia, $N^{\circ}$ 44, Vol. II, 2011, pp. 401 442.

- Rossenblit, Jaime, Centralidad Geográfica, marginalidad política: la región de Tacna y Arica y su comercio 1778 1841, DIBAM y Centro de Estudios Barros Arana, Santiago, 2013. 
- Serrano, Gonzalo, 1836 1839. Portales y Santa Cruz. Valparaíso y la Guerra contra la Confederación, Ediciones Universitarias de Valparaíso, Valparaíso, 2013.

- — Chile contra la Confederación, La Guerra en Provincias, Ril Editores, Valparaíso, 2017.

- Sobrevilla, Natalia, The caudillo of the Andes, Cambridge, Cambridge, United States of America, 2011.

- Sotomayor Valdés, Ramón, Historia de Chile, Academia Chilena de la Historia, 1965, Tomo II.

- Valdés, Magdalena, «Reclutamiento, Orden y Corrección Social. Colchagua ante la Guerra contra la Confederación Peruano Boliviana», Tesis para optar al grado de Licenciado en Historia (Profesora Guía Sol Serrano), Pontificia Universidad Católica de Chile, Santiago, 2007

- Valencia, Luis, El Pensamiento de O’Higgins, Editorial del Pacífico, S.A., Santiago, 1974.

- Vergara, Sergio, «Portales y el Ejército», en Bravo Lira, Bernardino (Compilador), Portales, el hombre y su obra: La consolidación del gobierno civil, Editorial Jurídica de Chile, Santiago, 1989, p. 87 116.

- Vicuña Mackenna, Benjamín, El Ostracismo del Jeneral D. Bernardo O'Higgins, Imprenta i Librería del Mercurio, Valparaíso, 1860.

$\longrightarrow$ Vida de O'Higgins, Universidad de Chile, Santiago, 1936. 